\title{
"A volatility-based approach to gold as a safe haven: can it explain the abnormalities in gold returns during periods of extreme financial adversity?"
}

\author{
Maria Alberta Oliveira (D https://orcid.org/0000-0003-2918-1354 \\ Carlos Santos (D https://orcid.org/0000-0002-5100-0794
}

Maria Alberta Oliveira and Carlos Santos (2016). A volatility-based approach to gold as a safe haven: can it explain the abnormalities in gold returns during periods of extreme financial adversity?. Investment Management and Financial Innovations, 13(3-1), 203-214. doi:10.21511/imfi.13(3-1).2016.06

ARTICLE INFO http://dx.doi.org/10.21511/imfi.13(3-1).2016.06

DOI Friday, 23 September 2016

RELEASED ON "Investment Management and Financial Innovations"

JOURNAL LLC "Consulting Publishing Company "Business Perspectives"

FOUNDER

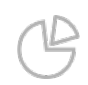

NUMBER OF FIGURES

0

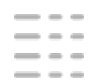

NUMBER OF TABLES

0

(c) The author(s) 2022. This publication is an open access article. 
Maria Alberta Oliveira (Portugal), Carlos Santos (Portugal)

\title{
A volatility-based approach to gold as a safe haven: can it explain the abnormalities in gold returns during periods of extreme financial adversity?
}

\begin{abstract}
In this paper, the authors provide an explanation of the abnormal behavior of gold returns between the $1^{\text {st }}$ of January 2008 and the $31^{\text {st }}$ of December 2013. The authors suggest a behavioral finance foundation to the fact that gold returns exceed those of a wide range of other assets over this period. The approach rests on the safe haven ( $\mathrm{SH}) \mathrm{motif}$ for flights to gold during heavy financial stress periods. The prevailing Baur-Lucey-McDermott paradigm on gold as a SH is shown to be insufficient, as it ignores the roles of volatility and risk preferences. The auhors suggest a formal SH definition, recovering those elements from behavioral finance. Contrary to the previous paradigm, the approach is dataconsistent, in the sample period. The authors find that gold is a SH for all stock markets considered, some exchange rates, and even Euro Area sovereign bonds (including German bunds). They estimate the SH risk premium in all cases. The authors find that investors perceive the distinction between good and bad volatility, and that they do not ask for excess returns when gold volatility is high for SH reasons. This is consistent with the literature on the low frequency of idiosyncratic shocks in the gold market. Furthermore, the authors find evidence that, in a period of high financial uncertainty, fund managers building portfolios consisting only of gold might be acting rationally, contrary to the finance common sense for normal periods. In fact, in the sample period, gold is even strictly dominant in meanvariance terms, when compared to equity.
\end{abstract}

Keywords: safe haven, gold, euro debt crisis, risk preferences, fund management.

JEL Classification: C22, C58, G01, G11, G15.

\section{Introduction}

The financial crisis of 2008-09 and the Euro Area (EA) sovereign debt crisis have spurred renewed interest on the topic of safe haven (SH) assets. Gold has merited special attention among traditional $\mathrm{SH}$ candidates, both from investors and academics. Such attention was mostly due to gold's outstanding performance in the three years that followed the Lehman Brothers bankruptcy. In particular, the troy ounce price, in the London Bullion Market (LBM), has risen about $145 \%$, from 776.85 USD, on the $15^{\text {th }}$ of September 2008, to 1898.25 USD on the $5^{\text {th }}$ of September 2011. By then, the EA crisis had long begun, with the Irish, the Greek and the Portuguese rescue packages being implemented. The time nexus between the two aforementioned crises and the gold rally seems clear.

Furthermore, gold troy ounce prices, in the LBM, were still of 1786 USD by early October 2012 . Again, by that date, both the second Greek rescue package and the Spanish bank bail-out ${ }^{1}$ had already been agreed upon. In spite of a decline in 2013, the price of gold was still well above 1200 USD per

(c) Maria Alberta Oliveira, Carlos Santos, 2016.

Maria Alberta Oliveira, Ph.D., Assistant Professor, ISMAI - University Institute of Maia, Portugal. Affiliated with UNICES - Reseach Unit in Business Sciences and Sustainability; and NECE - Research Unit in Business Sciences, Portugal.

Carlos Santos, Ph.D. with Habilitation, Professor of Econometrics; Católica Porto Business School, Universidade Católica Portuguesa (Porto), Portugal.

${ }^{1}$ Bialkowski et al. (2015) argue that the doubts about the viability of the banking sector and the international payments system have made the acquisition of gold a perfectly rational response from investors. troy ounce, by the $31^{\text {st }}$ of December, in the LBM. Figure 1 documents the behavior of gold prices over this period (see in Appendix).

The 2008-2013 period is also unique in the sense that stylized facts pertaining to the properties of gold returns, and to their relationship with those of other assets, appear to break down ${ }^{2}$. The usual positive skewness in the distribution of gold returns is not found in this period, suggesting that gold would not provide downside protection in a portfolio, contrary to what had been argued, inter alia, in Lucey et al. (2006) and Lucey (2011). Moreover, in this period, gold is not strictly dominated, in mean-variance terms, by any of a wide range of financial assets, and its volatility is lower than that of several stock markets. These facts contradict the standard claim that volatility would always be higher in the gold market than in bonds and even in equity markets (e.g., Flavin et al., 2014). Furthermore, although the literature argues that portfolios containing a small weight of gold shift the risk-return frontier to the left (Jaffe, 1989), with the optimal weight for gold suggested to be in the range of $6 \%$ to $25 \%$ (e.g., Lucey et al., 2006), in our reference period gold held in isolation outperforms, both in terms of risk and return, a wide range of portfolios made solely of equity (e.g., one reproducing the S\&P500 index). The claim that investors holding only gold would be worse off than those holding just equity (e.g., Flavin et al., 2014)

\footnotetext{
${ }^{2}$ Section 4.1 provides statistical support for the claims in this paragraph.
} 
may be untrue during abnormal periods. In short, from a fund manager's perspective, the existing knowledge would be a poor guide for decisionmaking from 2008 to 2013.

The recent literature on gold has not provided a data-consistent explanation of the $\mathrm{SH}$ motif for investors to hold this commodity in their portfolios, in periods of high uncertainty, such as that between 2008 and 2013. In our view, this is primarily the result of prevailing ambiguities in the understanding of the $\mathrm{SH}$ concept in the gold literature. In fact, recent papers on gold as a $\mathrm{SH}$ are dominated by the Baur-Lucey-McDermott paradigm (Baur and Lucey, 2010; Baur and McDermott, 2010), failing to take into account the roles of volatility and investors' risk preferences. Such frailties have also led to the absence of a well-established econometric method to test for gold as a SH, and to the lack of a framework to explain the aforementioned abnormalities in gold returns. All in all, it is not surprising that the empirical results in the literature on gold have often been contradictory.

Our paper addresses the question of whether the behavior of the gold market in this sample period is explained by the quest for a $\mathrm{SH}$. We departure from the existing literature on gold, both by clarifying the behavioral definition of a SH asset and by adjusting the methodology to test for gold as a $\mathrm{SH}$ accordingly. In particular, the influential BaurLucey-McDermott paradigm, whereby shifts in correlations between gold returns and those of other assets would be essential to identify SHs, is abandoned. Instead, we take advantage of earlier concepts in the finance literature that had not been used in this market, such as the SH risk premium, risk preferences, and flight-to-safety, to assess the hypothesis of gold as a $\mathrm{SH}$.

We also departure from the existing literature by adjusting the method to test for a SH. We improve on Flavin et al. (2014) by allowing for a continuum of volatility regimes, instead of only two, and on Baur and McDermott (2010) by checking for feedback relationships between the candidate $\mathrm{SH}$ market and the other markets. With respect to Joy (2011), we introduce a reverse causality test to determine the direction of capital flights.

This paper is organized as follows. Section 1 provides a critical overview of the literature on $\mathrm{SH}$ assets, with a particular emphasis on gold. Section 2 develops our formal SH definition, presenting the resulting research hypotheses and explaining the methodology. Section 3 describes the data. Section 4 presents and discusses the empirical results, highlighting how we succeed in solving some of the conundrums in the literature. Final section concludes the paper.

\section{Literature review}

In this section, the literature on SHs is divided according to whether or not the specific case of gold is addressed. Firstly, we provide an overview of the finance theory on traditional $\mathrm{SH}$ assets ${ }^{3}$, excluding gold, in order to retrieve its fundamental insights. On the second subsection, we address the recent literature on gold as a $\mathrm{SH}$, emerging from Baur and Lucey (2010). Finally, we discuss the approach of Flavin et al. (2014) to gold as a SH, as a first, albeit insufficient, departure from the Baur and Lucey (2010) benchmark.

1.1. Risk preferences, flight-to-safety and liquidity. SH definitions have been anchored in the concepts of volatility, risk preferences and flight-toliquidity, irrespective of whether one is looking at the academic literature or at practitioners' references. Indeed, taking the Financial Times Lexicon $^{4}$ as a benchmark, a SH is an asset that is favored in times of crisis because of its stability and ease of liquidation. This definition is remarkably similar to the conclusions of the academic literature survey of McCauly and McGuire (2009): a broad definition of SH points to assets with low market risk and high liquidity that are sought when investors are nervous of market losses.

These elements seem to be common across studies of traditional SH candidates. Looking at the appreciation of the USD in the early to mid-eighties, Froot and Thaler (1990) argue that a possible reason might be the perception of a SH currency, as investments in assets denominated in USD would be less risky than others. Kaul and Sapp (2006) conduct an event study regarding the intraday behavior of the USD bid-ask spread, during the Y2K episode, in the turn of the millennium. They notice a widening of the spread around the $31^{\text {st }}$ of August 1999, with mean reversion in the following days. The US were considered the better prepared country to cope with possible Y2K failures. In short, Kaul and Sapp (2006) relate the SH concept to the ideas of risk and flight-to-safety. They claim that a $\mathrm{SH}$ is an asset that investors are drawn to, in periods of market uncertainty.

Ranaldo and Söderlind (2010), considering also the case of the USD as a SH currency, establish a linkage between SHs and risk preferences. A decrease in risk aversion would lower the value of SH assets. In a similar way, for the same level of risk aversion, a smaller perception of market risk leads to higher-sell pressure of $\mathrm{SH}$ assets. $\mathrm{SH}$

\footnotetext{
${ }^{3}$ Some currencies (e.g., the USDand the JPY), and some government bonds (e.g., 10 years maturity US and German bonds) are traditionally seen as SHs.

${ }^{4}$ http://markets.ft.com/research/Lexicon.
} 
holders would benefit from higher returns (SH risk premium) whenever uncertainty would invade other markets.

Upper (2000) develops an event study regarding the behavior of government bonds as SH assets. The author looks at 10 year German bunds, during the LTCM / Russian crisis episode. His definition of SH rests on low risk and high liquidity, pointing to the aforementioned flight-to-safety and flight-toliquidity. Beber et al. (2009) investigate the differences in sovereign bond spreads in the EA and conclude that, in periods of high uncertainty, flightto-liquidity prevails over flight-to-safety. Investigating the same problem as Beber et al. (2009), Santis (2012) reaches an opposite conclusion: investors would care more about safety than liquidity, in times of financial turmoil.

The finance literature we have referred to in this subsection provides common conceptual references with respect to volatility, risk preferences and flights to and from certain markets. Moreover, it never establishes any confrontation between a $\mathrm{SH}$ and a hedge (e.g., McCauly and McGuire (2009) use the terms interchangeably). This is a noticeable contrast to the Baur-Lucey-McDermott paradigm.

1.2. Gold as a SH: shifting correlations between returns. The definitions in Baur and Lucey (2010) and in Baur and McDermott (2010), resting on correlations between the returns of the candidate $\mathrm{SH}$ and those of another asset or portfolio, lead to the need of distinguishing between a SH and a hedge. According to Baur and Lucey (2010), a SH asset would be one that would either be uncorrelated or negatively correlated with another asset or portfolio, under times of market stress. Differently, a hedge would be an asset that, on average, would have either a negative or zero correlation with another asset or portfolio. Baur and McDermott (2010) distinguish the cases of zero (negative) correlation, on average, corresponding to a weak (strong) hedge. In the same spirit, the authors distinguish between weak and strong SHs. Hence, both Baur and Lucey (2010) and Baur and McDermott (2010) assess the role of gold as a SH, using a definition that rests upon the different regimes in the correlations between returns during normal times, or even bullish markets, and during market stress conditions. There is no resemblance with the previous finance literature. In contrast with the definitions we have discussed in subsection 1.1, the authors leave no room for risk aversion, flight-to-safety, flight-toliquidity, and other behavioral issues.

Theauthors' SH definition lacks rigour. It is unclear what is understood by periods of "market stress". Baur and Lucey's (2010) empirical application points to these as periods where stockmarket returns are in the lower quantiles of their sample distribution. Baur and
McDermott (2010) even make the problem clearer by using three different approaches to identify periods of market stress. This imprecision is critical since the authors' assessment of whether gold might be acting as a SH entirely depends on the correct identification of such periods.

As a result of their definition, the Baur-LuceyMcDermott empirical approach to test for SHs rests on univariate GARCH-X models for gold returns. Both the returns of the other asset or portfolio, and dummy variables to account for market stress periods, are included in the mean equation as explanatory variables.

The empirical results in Baur and Lucey (2010) and Baur and McDermott (2010) are unreliable. The authors neglect possible multimodalities in the likelihood function resulting from the dummies in the mean equation (Doornik and Ooms, 2003). Furthermore, prior to choosing a univariate GARCH, they don't investigate feedback relationships between gold and the other assets' markets (endogeneity biases might exist). The model used in Baur and Lucey (2010) has the additional problem of including bond returns and equity returns simultaneously in the mean equation as conditioning variables, without any reference to possible multicollinearity issues ${ }^{5}$.

The research on whether gold could act as a SH was continued by Coudert and Raymond-Feingold (2011) and by Joy (2011). While the first authors were focused on gold and equity markets, Joy (2011) investigated whether gold was a SH for the USD. Both papers improve on the econometric shortcomings of Baur and Lucey (2010) and Baur and McDermott (2010). Indeed, Coudert and Raymond-Feingold (2011) avoid biases arising from an arbitrary selection of "market stress" periods by using the Pagan and Sossounov (2003) algorithm. Further, they allow for continuously changing covariances between returns, through a bivariate ARMA-GARCH specification. They avoid multimodalities in the likelihood function, as there were no dummies in their mean equation. Joy (2011) avoids possible endogeneity bias, allowing feedback from the foreign exchange market to the gold market. In fact, the author provides a joint analysis of the movements of gold returns and those of 16 pairs of USD exchange rates, accommodating changing conditional correlations with Engle's (2002) DCC MGARCH framework ${ }^{6}$.

\footnotetext{
${ }^{6}$ In fact, the DCC MGARCH is not a fully satisfactory solution to Joy's (2011) problem, since shifts in correlations are uninformative as to the origin of capital flights. As we shall discuss in subsection 2.3, a proper methodology should investigate whether the flight is originated on the gold maket or not.We shall suggest reverse causality tests to address this.
} 
Notwithstanding, conceptually, both papers explicitly use the $\mathrm{SH}$ definition suggested in the literature on gold by Baur and Lucey (2010) and Baur and McDermott (2010). In spite of the improved methodologies, the authors search shifts in correlations between the returns of gold and those of other assets. No insights into the roles of volatility, investors' risk preferences, or flights-tosafety are provided. Moreover, both papers assess the distinction between the hedge and $\mathrm{SH}$ roles of gold, which had traditionally been absent from the finance literature on SHs.

1.3. Discrete regime shifts in volatilities and gold as a SH. Flavin et al. (2014) provide the only departure from the correlations-shift paradigm, in the recent literature on gold as a SH. Their concern is with the decision making process of a fund manager aiming to choose an optimal SH asset to combine with equity, in a portfolio. The returns of each of the assets are allowed to depend on three factors: an idiosyncratic shock to the $\mathrm{SH}$ asset, an idiosyncratic shock to equity, and a common shock. The authors restrict each shock to be either in a high or in a low volatility regime. A total of eight $\left(2^{3}\right)$ possible states exist for the portfolio. Transitions between regimes are of the Markov-type. The SH candidates are gold and US bonds of different maturities.

The authors are clearly working with a fundamentally different approach to a SH definition. They are to be commended due to the critical role volatility regimes play, and for their explicit reference to the relevance of the fund manager's risk preferences. Indeed, to some extent, the finance literature on subsection 1.1 is recovered, and the Baur-Lucey-McDermott paradigm is abandoned. The distinction between a $\mathrm{SH}$ and a hedge is irrelevant in Flavin et al. (2014).

Notwithstanding, their definition of SH is of little practical use, as the authors are too restrictive. In fact, they consider that a $\mathrm{SH}$ asset is one whose first and second order moments are "insulated" from shocks to the other markets. This would entail four conditions: 1) the SH mean returns are immune to shocks in equity returns; 2) the volatility of the SH returns cannot be influenced by equity's volatility; 3 ) the SH mean returns cannot depend on stock markets' volatility; 4) the volatility of the $\mathrm{SH}$ returns cannot depend on shocks to the mean returns of equity. The overwhelming restrictions of their $\mathrm{SH}$ definition are implicitly acknowledged by the authors in their empirical study.

A second major shortcoming of Flavin et al. (2014) is their statistical approach to $\mathrm{SH}$ assessment. In practice, the authors fail to provide the fund manager with a clear rule on how to decide on the optimal SH candidate, from their regime switching model estimation results. In fact, their empirical analysis use sseveral $\mathrm{SH}$ selection methods ${ }^{7}$, with inconsistent conclusions.

Adding to this, the authors restrict the analysis to two states: high and low volatility. The resulting eight scenarios are the product of an arbitrary decision. As we shall discuss in section 2.3, a continuum of volatility regimes could be considered. Finally, although the authors allude to the fund manager's risk preferences, they do not retrieve from the data any conclusions as to those preferences, nor to the possible existence of a $\mathrm{SH}$ risk premium (in the spirit of Ranaldo and Söderlind (2010)).

\section{SH concept, implied research hypotheses and methodology}

2.1. SH Definition. The introduction and section 1 have established the need to clarify the understanding of a SH asset, in a formal way. The suggestion below follows the tradition of the finance literature, referred to in subsection 1.1. As such, we departure from the Baur-Lucey-McDermott paradigm.

Definition. Let $W$ be the candidate $\mathrm{SH}$, and $Z$ be some other financial asset or portfolio. Let $r_{W, t}$ and $r_{Z, t}$ be the rates of return, at time $t$, of the candidate $\mathrm{SH}$ and of the other asset or portfolio, respectively. Let $V_{t}(W)$ and $V_{t}(Z)$ be the corresponding volatilities. Denote by $\theta_{Z}$ the risk premium associated with the $\mathrm{SH}$ asset, by $\theta_{W, Z}$ the premium of investors' holding the SH when $V_{t}(Z)$ increases, and by $\theta_{Z, W}$ the premium of investors holding $Z$, when $V_{t}(W)$ increases.

An asset $W$ is a SH, with respect to another asset or portfolio $Z$, during a certain time period, if and only if the following conditions are simultaneously satisfied:

$$
\begin{aligned}
& \frac{\partial r_{W, t}}{\partial V_{t}(Z)}=\theta_{W, Z}>0, \\
& \frac{\partial r_{Z, t}}{\partial V_{t}(W)}=\theta_{Z, W} \leq 0, \\
& \frac{\partial r_{W, t}}{\partial V_{t}(W)}=\theta_{W} \leq 0 .
\end{aligned}
$$

Condition (1) reflects the SH concept summarized, inter alia, in Kaul and Sapp (2006): the SH is an asset investors are seeking in periods of market

\footnotetext{
${ }^{7}$ Flavin et al. (2014) use aportfolio variance decomposition, the relative contributions of each shock under each regime, and a correlations-based approach.
} 
uncertainty. The condition also comprises the idea of a SH risk premium, as suggested by Ranaldo and Söderlind (2010). Indeed, whenever demand for the SH increases, investors holding it in their portfolios may have increased returns.

Condition (2) improves on Joy (2011), in the sense that causality direction needs to be clarified for proper identification of the $\mathrm{SH}$ asset: increased volatility in other markets augments the returns of the SH (condition (1)), but the reverse does not occur.

Condition (3) is often implicit in the finance literature, but hardly ever discussed. In fact, if the returns of the $\mathrm{SH}$ asset are increasing, the SHmarket is experiencing augmented volatility, in comparison to normal times ${ }^{8}$. It would make no sense for investors to ask for a premium. In fact, they distinguish between "good" and "bad" volatility (see, inter alia, Patton and Sheppard, 2015).

2.2. Research hypotheses. The research question of this paper is related to finding out whether the behavior of the gold market, in the 2008-2013 periods, is driven by the quest for a SH. As such, the three conditions of the $\mathrm{SH}$ definition outlined motivate research hypotheses $\mathrm{H} 1-\mathrm{H} 3$ below. In practice, we shall need to check if gold is a $\mathrm{SH}$ in this period, for a variety of $Z$ assets, according to the aforementioned necessary conditions.

The choices we have implicitly made in the $\mathrm{SH}$ definition do not fully match the suggestions of the finance literature overviewed in subsection 1.1. In particular, we have chosen not to make flight-toliquidity and flight-to-safety necessary conditions for an asset to be a SH. The conflicting evidence in the literature as to the relative relevance investors give to safety and to liquidity ${ }^{9}$ has motivated our decision of not considering these as necessary conditions in a SH definition. Research hypotheses $\mathrm{H} 4-\mathrm{H} 5$ are related to that option.

Finally, in the introduction, we have described a number of abnormal features in the behavior of the gold returns in this period. Research hypotheses H6H7 are related to such abnormalities. They are included in order to check if our definition is dataconsistent.

$\mathrm{H} 1$ : When gold is a $\mathrm{SH}$, with respect to an asset $Z$, it exhibits a SH risk premium, that is $\theta_{W, Z}>0$.

$\mathrm{H} 2$ : When gold is a $\mathrm{SH}$, with respect to an asset $Z$, there is no positive feedback from its volatility to

\footnotetext{
${ }^{8}$ As argued in Flavin et al. (2014), SH assets have few idiosyncratic shocks. As such, their volatility increases reflect shocks in other markets and represent profitable opportunities.

9 This topic was addressed in section 1.1, with reference to the conflicting conclusions of Beber et al. (2009) and Santis (2012).
}

the returns of the markets investors are flying away from, that is $\theta_{Z, W} \leq 0$.

$\mathrm{H} 3$ : When gold is a $\mathrm{SH}$, with respect to an asset $Z$, investors do not require a risk premium for buying gold, in spite of its volatility, that is $\theta_{W} \leq 0$.

H4: Flight-to-liquidity is not a necessary condition for a SH definition.

H5: Flight-to-safety is not a necessary condition for a SH definition.

H6: Under extreme financial adversity, if gold is a $\mathrm{SH}$, an investor holding solely gold in his portfolio, might be acting rationally.

H7: Under extreme financial adversity, when gold is a SH for equity, it may outperform the stock market in mean-variance terms.

2.3. Methodology. We shall follow a multi-step method to answer our research question and to address the research hypotheses outlined. A preliminary GARCH $(1,1)$ model is estimated for all assets considered, including gold. This step is not reported in section 5, as it only serves the purpose of obtaining estimates for the conditional volatilities of all assets, in the sample period.

The second step is to estimate univariate GARCH-X models for gold returns and each alternative asset $Z$ (equations (1) and (2)). $V(Z)_{t}$ are the conditional volatilities obtained in the procedure described in the previous paragraph ${ }^{10}$ :

$$
\begin{aligned}
& r_{W, t}=\mu+\theta_{W, Z} V(Z)_{t}+u_{t}, \\
& h_{t}^{W, Z}=a_{0}+a_{1} u_{t-1}^{2}+\beta h_{t-1}^{W, Z} .
\end{aligned}
$$

The objective of this step is to test the null hypothesis: $H_{0}: \theta_{W, Z}=0$, against the alternative of a positive $\theta_{W, Z}$.

The third step is to identify the direction of causality. As such, for each asset $Z$, the following equations are estimated:

$$
\begin{aligned}
& r_{Z, t}=\mu+\theta_{Z, W} V(W)_{t}+v_{t}, \\
& h_{t}^{Z, W}=a_{0}+a_{1} u_{t-1}^{2}+\beta h_{t-1}^{Z, W} .
\end{aligned}
$$

The objective is to test the hypothesis: $\theta_{Z, W}=0^{11}$. Finally, with the aim of testing whether $\theta_{W}$ would, indeed, be non-positive for gold, we also need to estimate the GARCH-M model (e.g., Tsay, 2010) for gold returns, as described by equations (5) and (6).

$r_{W, t}=\mu+\theta_{W} V(W)_{t}+\varepsilon_{t}$

$h_{t}^{W, W}=a_{0}+a_{1} u_{t-1}^{2}+\beta h_{t-1}^{W, W}$.

\footnotetext{
${ }^{10}$ A robustness analysis not reported in the paper indicates that empirical conclusions would be identical if instead of estimated conditional volatilities, other proxies were used for $V(Z)_{t}$.

${ }^{11}$ In section 4 , we shall refer to these as reverse causality tests.
} 
The innovations in all the above models were assumed to be $t$-distributed, to account for excess kurtosis.

\section{Variables and data}

We use data covering the period between the $1^{\text {st }}$ of January 2008 and the $31^{\text {st }}$ of December 2013. We wish to test whether gold acts as a $\mathrm{SH}$ for a wide range of financial assets, with different levels of liquidity. Thus, we shall look at different stock, foreign exchange, bonds and commodity markets.

We have obtained daily data, referring to this sample period, for the following variables:

- gold prices (USD per troy ounce, in the LBM);

- stock market indices (S\&P500, FTSE100, EURONEXT100, DAX30 and ATHEX) ${ }^{12}$;

- Euro denominated exchange rates (USD/EUR, JPY/EUR, GBP/EUR and CHF/EUR) ${ }^{13}$;

- government bond prices (10 years-maturity US bonds; 10 years-maturity German bunds; the eMU index) ${ }^{14}$;

- Crude oil and silver prices.

All data were obtained from Thomson Reuters DataStream. Estimation results were obtained using the G@RCH package in Oxmetrics 7.

\section{Results and discussion}

4.1. Preliminary analysis. Table 1 provides summary statistics for each asset's log-returns over the sample period ${ }^{15}$.

It is worth noticing that gold's daily mean returns are positive $(0.045441 \%$, corresponding to a mean yearly compound rate of $18.03 \%$ ) and bigger than those of any other of the $Z$ assets. The claim (e.g., Flavin et al., 2014) that gold would exhibit negative mean excess returns, even in the medium run, contrary to equity and bond markets, fails between the $1^{\text {st }}$ of January 2008 and the $31^{\text {st }}$ of December 2013.

The burden of the crisis is clear for stock markets: on average, compound yearly losses were $37.78 \%$ for the ATHEX and $7.87 \%$ for the EURONEXT100, while yearly gains were as low as $0.32 \%$, for the FTSE100, $2.9 \%$ for the S\&P500, and $4 \%$ for the DAX30. In short, gold's yearly average return is more than 4 times that of the best performing stock index, in the sample period. Adding to this, gold's unconditional volatility,

\footnotetext{
12 We chose 4 of the most relevant stock market indices worldwide. Albeit being less relevant, the ATHEX was also included due to the severity of the Greek financial crisis.

${ }_{13}$ We chose Euro denominated exchange rates due to the uncertainty motivated EA debt crisis. It seems possible that investors would fly away from parking liquidity in Euros.

${ }^{14}$ The SH literature commonly studies bond markets, as these are usually seen as candidate $\mathrm{SHs}$, and not as assets investors would be flying away from (e.g., Upper, 2000). However, the 2008-9 financial crisis and the EA sovereign debt crisis might have reduced investors' confidence in government bonds. Contagion fears might even have affected the EA core. For this reason, German bunds are included along with the EMU index (a weighted price index for EA government bonds).

${ }^{15}$ Log-returns were not converted to percentages.
}

as measured by the standard deviation of its daily logreturns, is lower than that of any of the stock markets considered. This is the most significant difference with respect to the paradigm for the long run, in the finance literature (see, e.g., Flavin et al., 2014): gold would be expected to have lower returns and higher risk than equity.

In the FX market, the yearly compound average return of investors switching to Euros during the sample period is also poor. Compound mean yearly losses of $3.6 \%, 2.8 \%$ and $6.7 \%$ would occur for those who had originally parked liquidity in USD, JPY or CHF. The exception is the British Pound, allowing for an average yearly compound gain, for those switching from parking liquidity in GBP to doing so in Euros, of $2.95 \%$.

Contrary to the stock market, there is no strict meanvariance dominance in the foreign exchange market, since gold returns' standard deviation over the sample period is higher than the standard deviation of any of these 4 Euro exchange rates' returns.

With respect to bonds markets, Table 1 suggests that the 10 years-maturity German bunds strictly dominate the corresponding US bonds. The compound annual average return of $7.84 \%$ of the bunds is more than twice that of the US bonds (3.1\%), and the bunds' variance is smaller, in the sample period. The EMU index behaves similarly to the bunds. However, when compared to gold, all three assets have smaller average risk, and smaller average return. Hence, there is no strict dominance of gold over the bonds markets.

Finally, gold ${ }^{16}$ strictly dominates the two commodities considered. Compound yearly average returns are $3.3 \%$ for crude oil and $6.8 \%$ for silver, and both exhibit higher volatility than gold, during the sample period.

4.2. GARCH-M model for gold returns. In order to check whether gold acts as a SH in this period, we start by estimating the GARCH-M model for gold (equations (5) and (6)). Table 2 reports the results.

Table 2. Estimation results for gold market

Results of GARCHM $(1,1)$ model with mean of gold returns depending on its on volatility.

\begin{tabular}{|l|c|c|c|c|c|}
\hline & \multicolumn{2}{|c|}{ Gold mean } & \multicolumn{3}{c|}{ Conditional volatility } \\
\hline & $\mu$ & $\theta_{w}$ & $\alpha_{0}$ & $\alpha_{1}$ & $\beta$ \\
\hline Coeff. est. & 0.0008 & -0.8670 & 0.00000103 & 0.0448 & 0.9552 \\
\hline Std. err. & 0.0002 & 0.00001 & 0.00000043 & 0.0093 & 0.0093 \\
\hline$t$-stat. & $3.41^{* *}$ & $-72979.88^{* * *}$ & $2.4^{* *}$ & $4.83^{* *}$ & $103.1^{* * *}$ \\
\hline
\end{tabular}

Notes: $* * * * * ; *$ indicate statistical significance at the 0.01 , 0.05 and 0.10 level, respectively.

\footnotetext{
${ }^{16}$ The distribution of gold returns has a negative skewness coefficient, over the sample period, contradicting a stylized fact that would recommend gold as downside protection (e.g., Lucey, 2011). Nonetheless, the skewness coefficient is not statistically different from zero.
} 
The estimate of $Q_{W}$, the risk premium entrants in the gold market would demand due to gold's own volatility, is -0.867 . Furthermore, $V(W)_{t}$ is significant, at the $1 \%$ level. Hence, we conclude that $Q_{W}<0$, validating condition (3) of our SH definition, as well as research hypothesis H3. These results, combined with those of Table 1 pertaining gold's high mean returns in the sample period, suggest that investors, indeed, distinguish good from bad volatility, as referred in subsection 2.1 .

\subsection{Gold as a SH: the case of stock markets}

Table 3. Estimation results for stock market indices

Results of GARCH-X $(1,1)$ model with mean equation of gold returns depending on stock markets volatility.

\begin{tabular}{|c|c|c|c|c|c|c|}
\hline \multirow{5}{*}{ EURONEXT100 } & & \multicolumn{2}{|c|}{ Gold mean } & \multicolumn{3}{|c|}{ Conditional volatility } \\
\hline & & $\mu$ & $\theta_{w}$ & $\alpha_{0}$ & $\alpha_{1}$ & $\beta$ \\
\hline & Coeff. est. & 0.0008 & -0.8670 & 0.00000103 & 0.0448 & 0.9552 \\
\hline & Std. err. & 0.0002 & 0.00001 & 0.00000043 & 0.0093 & 0.0093 \\
\hline & $t$-stat. & $3.41^{* \star \star}$ & $-72979.88^{* * *}$ & $2.4^{* *}$ & $4.83^{\star \star \star}$ & $103.1^{* \star *}$ \\
\hline \multirow{3}{*}{ S\&P500 } & Coeff. est. & 0.0007 & 1.9015 & 0.0000007 & 0.0467 & 0.9533 \\
\hline & Std. err. & 0.0003 & 0.000011 & 0.0000004 & 0.0094 & 0.0094 \\
\hline & $t$-stat. & $2.65^{* \star *}$ & $165631.5^{\star \star \star}$ & $1.84^{*}$ & $4.98^{\star * \star}$ & $101.74^{\star \star *}$ \\
\hline \multirow{3}{*}{ FTSE100 } & Coeff. est. & 0.0006 & 1.1848 & 0.0000011 & 0.0454 & 0.9546 \\
\hline & Std. err. & 0.0002 & 0.000006 & 0.0000004 & 0.0095 & 0.0095 \\
\hline & $t$-stat. & $2.44^{\star *}$ & $209621.4^{\star * *}$ & $2.4^{* *}$ & $4.78^{* \star *}$ & $100.57^{* \star *}$ \\
\hline \multirow{3}{*}{ DAX } & Coeff. est. & 0.0005 & 1.3071 & 0.0000011 & 0.0454 & 0.9546 \\
\hline & Std. err. & 0.0002 & 0.0000057 & 0.0000004 & 0.0092 & 0.0092 \\
\hline & $t$-stat. & $2.21^{\star *}$ & $231263.3^{\star \star *}$ & $2.4^{* *}$ & $4.93^{* * *}$ & $103.76^{\star \star *}$ \\
\hline \multirow{3}{*}{ ATHEX Index } & Coeff. est. & 0.0007 & 0.027346 & 0.0000010 & 0.0450 & 0.9549 \\
\hline & Std. err. & 0.0002 & 0.000005 & 0.0000004 & 0.0093 & 0.0094 \\
\hline & $t$-stat. & $2.86^{\star \star *}$ & $602341^{* * *}$ & $2.37^{\star *}$ & $4.82^{\star \star \star}$ & $101.96^{\star \star \star}$ \\
\hline
\end{tabular}

Notes: $* * *, * * *$ indicate statistical significance at the $0.01,0.05$ and 0.10 level, respectively.

In order to test if gold is acting as a SH for stock markets, attention needs to be paid to Tables 3 and 4 . Table 3 reports the estimation results of equations (1) and (2) for the 5 market indices considered, while Table 4 reports results for models (3) and (4), allowing reverse causality tests. From Table 3, we learn that the estimated $Q_{W, Z}$ is positive and statistically significant, at $1 \%$, for all the indices. Thus, we conclude in favor of research hypothesis $\mathrm{H} 1$ for stocks, in the sample period. Condition (1) of our SH definition is met, when equity is the $Z$ asset. From Table 4, we conclude that there is no feedback from gold's volatility to any of the 5 stock markets, even at a $10 \%$ significance. We cannot reject $Q_{Z, W}=0$. Research hypothesis $\mathrm{H} 2$ and condition (2) of the $\mathrm{SH}$ definition are satisfied. Combining the results from Tables 2, 3 and 4, we find that our 3 conditions for gold to be a SH for stock markets are satisfied, in the sample period. Adding to this, when considering also that gold strictly dominates equity, in the risk-return trade off, during the sample period (Table 1), research hypothesis $\mathrm{H} 7$ is validated. An implication of our conclusions, following Ranaldo and Söderlind (2010), is that the estimates of $Q_{W, Z}$ may be interpreted as $\mathrm{SH}$ risk premiums. We estimate that, on average, an increase in daily conditional volatility of $1 / 1000$ in the S\&P500 index would lead to an increase in daily gold log-returns of $0.0019015^{17}$. The estimated effects of the other markets volatility on gold returns would be of 0.0013071 for the DAX, 0.0011848 for the FTSE100, 0.00106742 for the EURONEXT100, and 0.000027346 for the ATHEX. These results are robust, in the sense that the Athens stock exchange is the less liquid of these markets, thus, causing the smaller impact on gold returns, while flights from the US market cause the biggest.

Table 4. Estimation results for stock market indices - reverse causality test

Results of GARCH-X $(1,1)$ model with mean equation of gold returns depending on stock markets volatility.

\begin{tabular}{|c|l|c|c|c|c|c|}
\hline \multirow{2}{*}{ EURONEXT100 } & \multicolumn{2}{|c|}{ Gold mean } & \multicolumn{3}{c|}{ Conditional volatility } \\
\cline { 3 - 7 } & & $\mu$ & $\theta_{w}$ & $\alpha_{0}$ & $\alpha_{1}$ \\
\cline { 2 - 7 } & Coeff. est. & 0.0007 & -0.6493 & 0.0000026 & 0.0914 \\
\hline
\end{tabular}

\footnotetext{
${ }^{17}$ Unit increases in conditional volatility do not occur when working with daily log-returns. We have chosen to interpret SH risk premia with reference to changes in conditional volatilities of $1 / 1000$.
} 
Table 4 (cont.). Estimation results for stock market indices - reverse causality test

\begin{tabular}{|c|c|c|c|c|c|c|}
\hline \multirow{2}{*}{ EURONEXT100 } & & \multicolumn{2}{|c|}{ Gold mean } & \multicolumn{3}{|c|}{ Conditional volatility } \\
\hline & & $\mu$ & $\theta_{w}$ & $\alpha_{0}$ & $\alpha_{1}$ & $\beta$ \\
\hline & Std. err. & 0.0003 & 0.6556 & 0.0000011 & 0.0177 & 0.0180 \\
\hline & $t$-stat. & $2.38^{* *}$ & -0.99 & $2.45^{* *}$ & $5.16^{* * *}$ & $49.81^{* \star *}$ \\
\hline \multirow{3}{*}{ S\&P500 } & Coeff. est. & 0.0008 & -0.8937 & 0.0000010 & 0.0928 & 0.9054 \\
\hline & Std. err. & 0.0003 & 1.3080 & 0.0000004 & 0.0151 & 0.0147 \\
\hline & $t$-stat. & $3.08^{* * *}$ & -0.68 & $2.28^{\star \star}$ & $6.15^{\star \star \star}$ & $61.72^{\star \star \star}$ \\
\hline \multirow{3}{*}{ FTSE100 } & Coeff. est. & 0.0007 & -0.6263 & 0.0000018 & 0.0873 & 0.9034 \\
\hline & Std. err. & 0.0002 & 0.5260 & 0.0000008 & 0.0167 & 0.0171 \\
\hline & $t$-stat. & $2.75^{\star \star \star}$ & -1.19 & $2.38^{\star \star}$ & $5.23^{\star * \star}$ & $52.92^{\star \star *}$ \\
\hline \multirow{3}{*}{ DAX } & Coeff. est. & 0.0010 & -0.7148 & 0.0000019 & 0.0875 & 0.9094 \\
\hline & Std. err. & 0.0003 & 0.6679 & 0.0000010 & 0.0163 & 0.0152 \\
\hline & $t$-stat. & $3.46^{* * *}$ & -1.07 & $1.86^{*}$ & $5.37^{\star \star \star}$ & $59.83^{\star \star *}$ \\
\hline \multirow{3}{*}{ ATHEX Index } & Coeff. est. & -0.0006 & 0.4839 & 0.0000292 & 0.0827 & 0.8601 \\
\hline & Std. err. & 0.0005 & 1.0520 & 0.0000085 & 0.0165 & 0.0255 \\
\hline & $t$-stat. & -1.17 & 0.46 & $3.43^{* * *}$ & $5.01^{* * *}$ & $33.73^{\star \star \star}$ \\
\hline
\end{tabular}

Notes: ***,**; * indicate statistical significance at the $0.01,0.05$ and 0.10 level, respectively.

In short, conclusions for $\theta_{W}, \theta_{W, Z}$ and $\theta_{Z, W}$ show that investors fly away from equity markets as their volatility rises, feeding the increasing returns of the gold market. As gold returns increase, so does its volatility. Notwithstanding, investors flying to gold are not averse to its own volatility, as they understand it as a result of growing returns and not of idiosyncratic shocks. The fact that entrants in the gold market are willing to endure a negative risk premium constitutes evidence that they distinguish between good and bad volatility (see, e.g., Patton and Sheppard, 2015). Our results are coherent with the findings in Flavin et al. (2014) showing that a coincidence of high volatility regimes in equity and gold, in the absence of gold idiosyncratic shocks, usually implies that gold returns are increasing.

4.4. Gold as a SH: Euro exchange rates. Table 5 provides estimation results of equations (1) and (2) for each of the 4 Euro exchange rate pairs. The condition $\theta_{W, Z}>0$ is satisfied, at $1 \%$, for the returns of the USD/EUR and the CHF/EUR exchange rates. Condition (1) in the SH definition is verified.

From Table 5, we also learn that neither the conditional volatility of the JPY/EUR returns nor that of the GBP/EUR returns are statistically significant, in the respective mean equations for gold returns, even at a $10 \%$ significance. Thus, gold is not a $\mathrm{SH}$ for investors who have moved from parking liquidity in JPY or in GBP to Euros. Condition (1) does not hold in these cases.

Table 6 shows that condition $\theta_{Z, W}=0$ holds for the 4 Euro exchange rates. Conditions (1), (2) and (3) of the SH definition are met for gold with respect to the USD/EUR and the CHF/EUR pairs. Thus, gold is a $\mathrm{SH}$ for those pairs, in this period. Research hypotheses H1-H3 hold in these 2 cases.

The estimates of $\theta_{W, Z}$ for the USD/EUR and the CHF/EUR pairs may be interpreted as $\mathrm{SH}$ risk premiums. In fact, an increase of $1 / 1000$ in the conditional volatility of the USD/EUR exchange rate returns has an estimated average impact on gold returns of 0.0123019 . The impact of a similar increase in the conditional volatility of the CHF/EUR exchange rate returns is estimated to be of 0.0004359 . The magnitude of the estimates of $\theta_{W, Z}$ is coherent, since the USD/EUR market is much more liquid than the CHF/EUR market (Karnaukh et al., 2015). Hence, flights to gold induced by the first market are more meaningful.

Table 5. Estimation results for Euro exchange rates

Results of GARCH-X $(1,1)$ model with mean equation of gold returns depending on Euro exchange rate returns' volatility.

\begin{tabular}{|l|l|c|c|c|c|c|}
\hline \multirow{4}{*}{ USD/EUR } & \multicolumn{2}{|c|}{ Gold mean } & \multicolumn{3}{c|}{ Conditional volatility } \\
\cline { 2 - 7 } & & $\mu$ & $\theta_{w}$ & $\alpha_{0}$ & $\alpha_{1}$ & $\beta$ \\
\cline { 2 - 7 } & Coeff. est. & -0.0002 & 12.3019 & 0.0000026 & 0.0611 & 0.9263 \\
\cline { 2 - 7 } & Std. err. & 0.0003 & 3.5220 & 0.0000008 & 0.0115 & 0.0134 \\
\cline { 2 - 7 } & $t$-stat. & -0.51 & $3.49^{* * *}$ & $3.08^{* * *}$ & $5.32^{* * *}$ & $69.33^{* * *}$ \\
\hline \multirow{2}{*}{ CHF/EUR } & Coeff. est. & 0.0007 & 0.4359 & 0.0000010 & 0.0451 & 0.9549 \\
\cline { 2 - 7 } & Std. err. & 0.0002 & 0.000005 & 0.0000004 & 0.0093 & 0.0093 \\
\hline
\end{tabular}


Table 5 (cont.). Estimation results for Euro exchange rates

Results of GARCH-X $(1,1)$ model with mean equation of gold returns depending on Euro exchange rate returns' volatility.

\begin{tabular}{|c|c|c|c|c|c|c|}
\hline \multirow{2}{*}{ USD/EUR } & & \multicolumn{2}{|c|}{ Gold mean } & \multicolumn{3}{|c|}{ Conditional volatility } \\
\hline & & $\mu$ & $\theta_{w}$ & $\alpha_{0}$ & $\alpha_{1}$ & $\beta$ \\
\hline & $t$-stat. & $2.91^{* * *}$ & $83728.39^{\star \star *}$ & $2.403142^{\star \star *}$ & $4.83^{\star \star *}$ & $102.3063^{* * *}$ \\
\hline \multirow{3}{*}{ JPY/EUR } & Coeff. est. & 0.0006 & 2.4346 & 0.0000012 & 0.0424 & 0.9545 \\
\hline & Std. err. & 0.0003 & 1.7810 & 0.0000006 & 0.0099 & 0.0095 \\
\hline & $t$-stat. & $2.03^{\star *}$ & 1.37 & $1.88^{*}$ & $4.3^{\star \star \star}$ & $100.01^{* * *}$ \\
\hline \multirow{3}{*}{ GBP/EUR } & Coeff. est. & 0.0008 & -4.2345 & 0.0000012 & 0.0422 & 0.9543 \\
\hline & Std. err. & 0.0003 & 5.6510 & 0.0000006 & 0.0098 & 0.0095 \\
\hline & $t$-stat. & $2.85^{\star \star *}$ & -0.75 & $1.93^{*}$ & $4.32^{* * *}$ & $100.19^{* * *}$ \\
\hline
\end{tabular}

Notes: ***,**; * indicate statistical significance at the $0.01,0.05$ and 0.10 level, respectively.

Finally, we shall use this subsection to draw two other fundamental conclusions. Firstly, the results allow us to confirm research hypothesis H4. In spite of the higher liquidity of the USD/EUR market (see, e.g., Karnaukh et al., 2015), gold is a $\mathrm{SH}$ for investors holding USD that are considering to park their cash in Euros. In the sample period, increases in the volatility of the USD/EUR returns drives investors to the less liquid gold market. Secondly, given that gold is not strictly dominated in mean-variance terms by any of these 2 exchange rate pairs (as seen in subsection 4.1) for which it provides a $\mathrm{SH}$, research hypothesis $\mathrm{H} 6$ is validated. In fact, depending on the investors' risk preferences, a portfolio consisting solely of gold might be a rational choice. A fund manager with USD liquidity to allocate between Euros and gold, might chose to hold only gold, in a period such as that of our sample (a corner solution).

Table 6. Estimation results for Euro exchange rates - reverse causality test

Results of GARCH-X $(1,1)$ model with mean equation for exchange rate returns depending on gold's volatility.

\begin{tabular}{|c|c|c|c|c|c|c|}
\hline \multirow{5}{*}{ USD/EUR } & & \multicolumn{2}{|c|}{ Gold mean } & \multicolumn{3}{|c|}{ Conditional volatility } \\
\hline & & $\mu$ & $\theta_{w}$ & $\alpha_{0}$ & $\alpha_{1}$ & $\beta$ \\
\hline & Coeff. est. & 0.0001 & -0.4938 & 0.00000025 & 0.0327 & 0.9621 \\
\hline & Std. err. & 0.0002 & 0.3564 & 0.00000018 & 0.0070 & 0.0081 \\
\hline & $t$-stat. & 0.85 & -1.39 & 1.40 & $4.69^{* \star \star}$ & $119.17^{\star \star \star}$ \\
\hline \multirow{3}{*}{ CHF/EUR } & Coeff. est. & -0.00001 & -0.0822 & 0.000000014 & 0.0451 & 0.9549 \\
\hline & Std. err. & 0.00003 & 0.0713 & 0.000000003 & 0.0093 & 0.0093 \\
\hline & $t$-stat. & -0.48 & -1.15 & $4.18^{\star \star *}$ & $4.83^{* \star \star}$ & $102.31^{\star \star \star}$ \\
\hline \multirow{3}{*}{ JPY/EUR } & Coeff. est. & 0.0002 & -0.2708 & 0.0000016 & 0.0565 & 0.9245 \\
\hline & Std. err. & 0.0002 & 0.4961 & 0.0000007 & 0,0135 & 0.0185 \\
\hline & $t$-stat. & 1.13 & -0.55 & $2.18^{\star *}$ & $4.18^{\star \star \star}$ & $49.87^{\star \star \star}$ \\
\hline \multirow{3}{*}{ GBP/EUR } & Coeff. est. & 0.00002 & -0.0158 & 0.0000004 & 0.0523 & 0.9369 \\
\hline & Std. err. & 0.0001 & 0.2750 & 0.0000002 & 0.0102 & 0.0123 \\
\hline & $t$-stat. & 0.14 & -0.06 & $2.05^{* *}$ & $5.1^{* \star *}$ & $76.17^{\star * *}$ \\
\hline
\end{tabular}

Notes: $* * *, * * *$ indicate statistical significance at the $0.01,0.05$ and 0.10 level, respectively.

4.5. Gold as a SH: bond markets. Tables 7 and 8 refer to bond markets, reporting estimation results for equations (1), (2), (3) and (4). From Table 7, we learn that gold is not a SH for US government bonds with 10 years-maturity, even at a $10 \%$ significance. This result is coherent with the observations in Flavin et al. (2014), regarding the relationship between gold and US bonds of this maturity. Condition (1) in the SH definition, $\theta_{W, Z}>0$, is met for the 10 years-maturity German bunds and for the EMU index, at 1\% significance. Table 8 shows that the condition $\theta_{Z, W}=0$ is also satisfied for both assets even at $10 \%$, proving there is no reverse causality effect between gold's volatility and the bonds' market. 
Table 7. Estimation results for government bonds

Results of GARCH-X $(1,1)$ model within mean equation of gold returns depending on bonds' volatility.

\begin{tabular}{|c|c|c|c|c|c|c|}
\hline \multirow{5}{*}{$\begin{array}{l}\text { German Bund } \\
10 \mathrm{yr}\end{array}$} & & \multicolumn{2}{|c|}{ Gold mean } & \multicolumn{3}{|c|}{ Conditional volatility } \\
\hline & & $\mu$ & $\theta_{w}$ & $\alpha_{0}$ & $\alpha_{1}$ & $\beta$ \\
\hline & Coeff. est. & 0.0007 & 4.6181 & 0.000001 & 0.0451 & 0.9549 \\
\hline & Std. err. & 0.0003 & 0.0000001 & 0.0000004 & 0.0094 & 0.0094 \\
\hline & $t$-stat. & $2.63^{\star \star *}$ & $72428795^{\star * *}$ & $2.38^{* *}$ & $4.82^{\star \star \star}$ & $102.01^{* \star *}$ \\
\hline \multirow{3}{*}{$\begin{array}{l}\text { US Gov. } 10 \mathrm{yr} \\
\text { Bonds }\end{array}$} & Coeff. est. & 0.0007 & 2.0354 & 0.0000012 & 0.0426 & 0.9545 \\
\hline & Std. err. & 0.0002 & 6.2860 & 0.0000006 & 0.0099 & 0.0097 \\
\hline & $t$-stat. & $2.3^{* *}$ & 0.32 & $1.91^{*}$ & $4.29^{\star \star \star}$ & $98.55^{\star \star \star}$ \\
\hline \multirow{3}{*}{ EMU Index } & Coeff. est. & 0.0007 & 4.5834 & 0.000001 & 0.0451 & 0.9549 \\
\hline & Std. err. & 0.0003 & 0.0000001 & 0.0000004 & 0.0094 & 0.0094 \\
\hline & $t$-stat. & $2.63^{* * \star}$ & $77843071^{* * *}$ & $2.39^{* *}$ & $4.82^{\star * \star}$ & $102.01^{* \star *}$ \\
\hline
\end{tabular}

Notes: ***,**; * indicate statistical significance at the $0.01,0.05$ and 0.10 level, respectively.

Combining results from table 2,7 and 8 we conclude that gold is a SH for10 years- maturity German bunds and for the EMU index. Research hypotheses $\mathrm{H} 1-\mathrm{H} 3$ are validated for these assets. This conclusion shows that the conjecture in footnote 14 is also confirmed.

The fact that gold is a SH for the German bunds, whose unconditional volatility over the sample period is smaller (see subsection 4.1), confirms research hypothesis H5: flight-to-safety is not a necessary condition for the SH definition. Again, our analysis confirms that investors are not afraid of good volatility, even if the $\mathrm{SH}$ market is more volatile than the original market.

We estimate SH risk premiums for the German bunds and for the EMU index. On average, when the 10 years-maturity bunds returns' volatility increases by $1 / 1000$, gold returns are estimated to increase by 0.0046181 . The estimated $\mathrm{SH}$ premium of the EMU index volatility is 0.0045834 .

Table 8. Estimation results for Government Bonds - reverse causality test

Results of GARCH-X $(1,1)$ model with mean equation of bond returns depending on gold's volatility.

\begin{tabular}{|c|c|c|c|c|c|c|}
\hline \multirow{5}{*}{$\begin{array}{l}\text { German Bund } \\
10 \mathrm{yr}\end{array}$} & & \multicolumn{2}{|c|}{ Gold mean } & \multicolumn{3}{|c|}{ Conditional volatility } \\
\hline & & $\mu$ & $\theta_{w}$ & $\alpha_{0}$ & $\alpha_{1}$ & $\beta$ \\
\hline & Coeff. est. & 0.0001 & 0.1699 & 0.0000 & 0.0506 & 0.9374 \\
\hline & Std. err. & 0.0001 & 0.1825 & 0.0000 & 0.0120 & 0.0158 \\
\hline & $t$-stat. & 1.35 & 0.96 & $1.68^{*}$ & $3.98^{* * *}$ & $54.80^{* * *}$ \\
\hline \multirow{3}{*}{$\begin{array}{l}\text { US Gov. } 10 \mathrm{yr} \\
\text { Bonds }\end{array}$} & Coeff. est. & 0.0001 & 0.2486 & 0.0000002 & 0.0474 & 0.9449 \\
\hline & Std. err. & 0.0001 & 0.2379 & 0.0000001 & 0.0108 & 0.0126 \\
\hline & $t$-stat. & 0.46 & 1.05 & $1.77^{*}$ & $4.4^{* \star \star}$ & $75.05^{\star \star \star}$ \\
\hline \multirow{3}{*}{ EMU Index } & Coeff. est. & 0.0001 & 0.1699 & 0.0000 & 0.0506 & 0.9374 \\
\hline & Std. err. & 0.0001 & 0.1825 & 0.0000 & 0.0120 & 0.0157 \\
\hline & $t$-stat. & 1.34 & 0.96 & $1.68^{\star}$ & $3.98^{* * *}$ & $5490^{* * *}$ \\
\hline
\end{tabular}

Notes: $* * *, * * ; *$ indicate statistical significance at the $0.01,0.05$ and 0.10 level, respectively.

4.6. Gold as a SH: crude oil and silver. Table 9 provides estimation results for equations (1) and (2), when gold returns are allowed to depend on the conditional volatilities of crude oil returns (top panel) and of silver returns (lower panel). Results show that gold is not a $\mathrm{SH}$ for either of these commodities, even at a $10 \%$ significance. During the sample period, there were no significant flights from these commodities to the gold market induced by volatility changes in silver's returns or in crude oil's returns.

Table 9. Estimation results for commodities

Results of GARCH-X $(1,1)$ model with mean equation for gold returns depending on commodities returns' volatility.

\begin{tabular}{|l|l|c|c|c|c|c|}
\hline \multirow{3}{*}{ Crude oil } & \multirow{2}{*}{} & \multicolumn{2}{|c|}{ Gold mean } & \multicolumn{2}{c|}{ Conditional volatility } \\
\cline { 3 - 7 } & & $\mu$ & $\theta_{w}$ & $\alpha_{0}$ & $\alpha_{1}$ \\
\cline { 2 - 7 } & Coeff. est. & 0.0007 & 0.0748 & 0.000001 & 0.0422 \\
\hline & Std. err. & 0.0003 & 0.4308 & 0.0000006 & 0.0098 \\
\cline { 2 - 7 } & $t$-stat. & $2.55^{\star *}$ & 0.17 & $1.91^{*}$ & 4.0095 \\
\hline
\end{tabular}


Table 9 (cont.). Estimation results for commodities

\begin{tabular}{|l|l|c|c|c|c|c|}
\hline \multirow{2}{*}{ Crude oil } & & \multicolumn{2}{|c|}{ Gold mean } & \multicolumn{2}{c|}{ Conditional volatility } \\
\cline { 3 - 7 } & & $\mu$ & $\theta_{w}$ & $\alpha_{0}$ & $\alpha_{1}$ \\
\hline \multirow{3}{*}{ Silver } & Coeff. est. & 0.0008 & -0.1697 & 0.0000012 & 0.0422 \\
\cline { 2 - 7 } & Std. err. & 0.0003 & 0.2004 & 0.0000006 & 0.0097 \\
\cline { 2 - 7 } & $t$-stat. & $2.96^{* * *}$ & -0.85 & $1.91^{*}$ & $4.35^{* *}$ \\
\hline
\end{tabular}

Notes: ***,**; * indicate statistical significance at the $0.01,0.05$ and 0.10 level, respectively.

\section{Conclusion}

In this paper, a careful analysis of the behavior of the gold market is conducted for the period between the $1^{\text {st }}$ of January 2008 and the $31^{\text {st }}$ of December 2013. Our baseline hypothesis is that the peculiar behavior gold exhibits are closely related to its role as a $\mathrm{SH}$. We suggest a volatility-based definition of a $\mathrm{SH}$, with sound behavioral foundations. Indeed, risk preferences play a pivotal role in our definition, in a fundamental departure from the Baur-Lucey-McDermott paradigm. In fact, those authors had defined SHs resting only on shifts in correlations between returns during so-called "market stress" periods.

We have also developed a modified methodology to test for SHs. We trust our suggestion to be coherent with the features we associate with the $\mathrm{SH}$ asset in the new definition. Moreover, we trust that it overcomes the econometric pitfalls in the earlier literature, discussed in subsections 1.2 and 1.3.

In this paper, we find that gold is a $\mathrm{SH}$ for 5 stock stock markets, for investors who had parked their money in Euros coming from the US dollar or from the Swiss franc, for the sovereign bonds market index in the EA, and even for 10 years-maturity German bunds. Gold was not found to be a $\mathrm{SH}$ for 10 years-maturity US government bonds, for commodities such as oil or silver, and for investors parking their liquidity in Euros coming from the Japanese yen or from the British pound. In all the cases where we have concluded in favour of gold being a $\mathrm{SH}$, estimates of the so-called $\mathrm{SH}$ risk premium (Ranaldo and Söderlind, 2010) were provided.

Our results are shown to be data-consistent, and our approach is able to account for golds' returns abnormalities in the sample period. The earlier paradigm, by failing to identify clearly that gold is a SH against stock markets, would not even understand the trigger for the gold rally. A hedge motif, according to their definition of hedge, would not apply in this crisis period.

Our results are also coherent with the stylized facts described, inter alia, in Flavin et al. (2014), namely in what concerns the relationship between gold and equity, and in what concerns gold and 10 yearsmaturity US bonds.

A different research problem, not addressed in this paper, is the extent to which herding behavior has been relevant in this period. We agree with Bialkowski et al. (2015) in that, if a gold bubble existed, it was largely rational, given the extension of the crisis period, and its impact on banks. Nonetheless, we trust the herding part of the bubble would deserve further research.

\section{References}

1. Baur, D.G. and Lucey, B.M. (2010). Is Gold a Hedge or a Safe Haven? An Analysis of Stocks, Bonds and Gold, Financial Review, 45, pp. 217-229.

2. Baur, D.G. and McDermott, T.K. (2010). Is gold a safe haven? International evidence, Journal of Banking and Finance, 34, pp. 1886-1898.

3. Beber, A., Brandt, M.W. and Kavajecz, K.A. (2009). Flight-to-safety or flight-to-liquidity? Evidence from the euro-area bond market, Review of Financial Studies, 22, pp. 925-957.

4. Białkowski, J., Bohl, M.T., Stephan, P.M. and Wisniewski, T.P. (2015). The gold price in times of crisis, International Review of Financial Analysis, 41, pp. 329-339.

5. Coudert, V.and Raymond-Feingold, H. (2011). Gold and financial assets: Are there any safe havens in bear markets? Economics Bulletin, 31, pp. 1613-1622.

6. Doornik, J.A. and Ooms, M. (2003). Computational aspects of maximum likelihood estimation of autoregressive fractionally integrated moving average models, Computational Statistics \& Data Analysis, 42(3), pp. 333-348.

7. Engle, R. (2002). Dynamic Conditional Correlation, Journal of Business \& Economic Statistics, 20, pp. 339-350.

8. Flavin, T.J., Morley, C.E. and Panopoulou, E. (2014). Identifying safe haven assets for equity investors through an analysis of the stability of shock transmission, Journal of International Financial Markets, Institutions and Money, 33, pp. 137-154.

9. Froot, K.A. and Thaler, R.H. (1990). Anomalies: Foreign Exchange, Journal of Economic Perspectives, 4, pp. 179-192.

10. Jaffe, J.K. (1989). Gold and gold stocks as investments for institutional portfolios, Financial Analysts Journal, 45 (2), pp. 53-59. 
11. Joy, M. (2011). Gold and the US dollar: Hedge or haven? Finance Research Letters, 8, pp. 120-131.

12. Kaul, A. and Sapp, S. (2006). Y2K fears and safe haven trading of the U.S. dollar, Journal of International Money and Finance, 25, pp. 760-779.

13. Karnaukh, N., Ranaldo, A. and Söderlind, P. (2015). Understanding FX Liquidity, Review of Financial Studies, 28 (11), pp. 3073-3108.

14. Lucey, B.M. (2011). What do Academics Think They Know About Gold? The Alchemist, 62, pp. 12-14.

15. Lucey, B.M., Poti, V. and Tully, E. (2006). International PortfolioFormation, Skewness and the Role of Gold, Frontiers in Finance and Economics, 3(1), pp. 49-68.

16. McCauley, R.N. and McGuire, P. (2009). Dollar appreciation in 2008: safe haven, carry trades, dollar shortage and overhedging, BIS Quarterly Review, December, pp. 85-93.

17. Pagan, A.R. and Sossounov, K.A. (2003). A simple framework for analysing bull and bear markets, Journal of Applied Econometrics, 18, pp. 23-46.

18. Patton, A. J. and Sheppard, K. (2015). Good Volatility, Bad Volatility: Signed Jumps and the Persistence of Volatility, Review of Economics and Statistics, 97 (3), pp. 683-697.

19. Ranaldo, A. and Söderlind, P. (2010). Safe Haven Currencies, Review of Finance, 14 (3), pp. 385-407.

20. Santis, R.A. (2012). The Euro Area Sovereign Debt Crisis: Safe Haven, Credit Rating Agencies and the Spread of the Fever from Greece, Ireland and Portugal, European Central Bank Working Paper, 1419, February.

21. Tsay, R. (2010). Analysis of Finantial Time Series, $3^{\text {rd }}$ Edition, Wiley.

22. Upper, C. (2000). How Safe Was the "Safe Haven"? Financial Market Liquidity during the 1998 Turbulences, Deutsche Bundesbank Working Paper, 1/2000, February.

\section{Appendix}

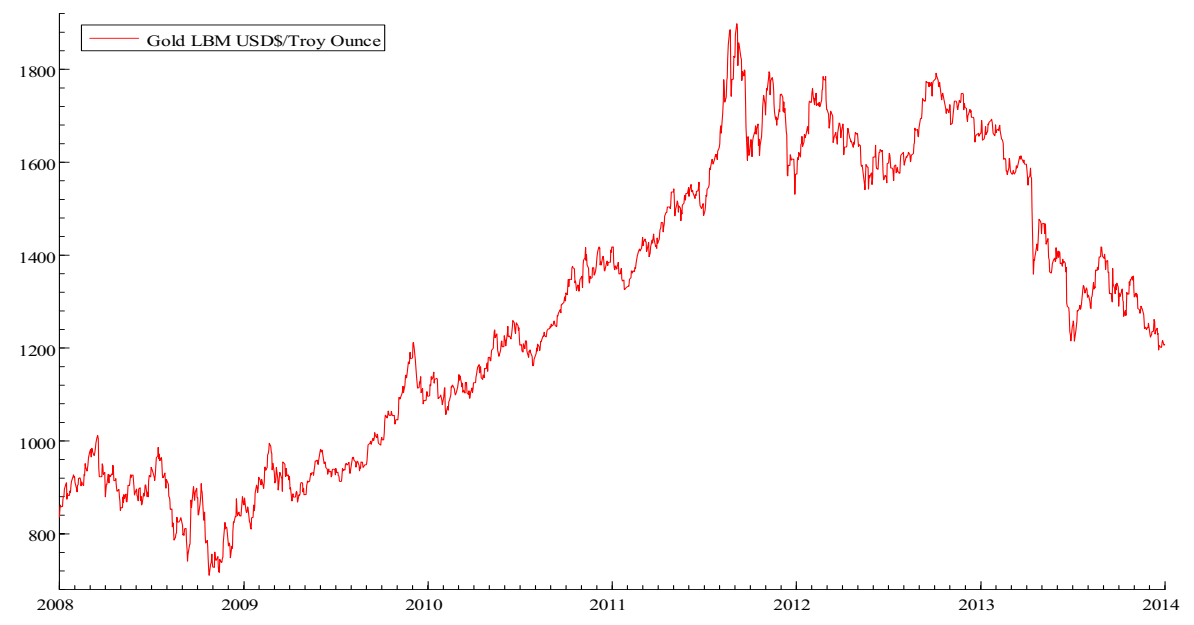

Fig. 1. Price of gold Troy Ounce (USD), from 2008 to 2014

Table 1. Descriptive statistics for returns of gold and $Z$ assets for the sample period

\begin{tabular}{|l|c|c|c|c|c|c|}
\hline & Mean & Std. Dvn. & Skewness & Excess Kurtosis & Minimum & Maximum \\
\hline Gold & 0.00045441 & 0.01353 & -0.29733 & 3.605 & -0.071434 & 0.068653 \\
\hline Crude Oil & 0.000087487 & 0.018465 & -0.20977 & 3.3045 & -0.092056 & 0.097685 \\
\hline Silver & 0.00017995 & 0.026307 & -0.41195 & 7.7302 & -0.18693 & 0.18279 \\
\hline S\&P500 & 0.000078395 & 0.014894 & -0.009373 & 10.051 & -0.10136 & 0.10945 \\
\hline EURONEXT100 & -0.00022439 & 0.016055 & 0.071047 & 5.5554 & -0.089511 & 0.10322 \\
\hline FTSE100 & $8.7565 E-06$ & 0.014678 & -0.082435 & 6.5909 & -0.092656 & 0.093843 \\
\hline DAX & 0.00010795 & 0.01598 & 0.10584 & 5.9021 & -0.074335 & 0.10797 \\
\hline ATHEX & -0.0012993 & 0.022643 & 0.14061 & 2.3084 & -0.10214 & 0.13431 \\
\hline 10 yr Bunds & 0.00020702 & 0.0041382 & 0.07814 & 1.2261 & -0.015232 & 0.022473 \\
\hline 10 yr US Gov bonds & 0.000083596 & 0.0056733 & 0.10892 & 2.7149 & -0.028735 & 0.040529 \\
\hline EMU & 0.00020591 & 0.0041393 & 0.07807 & 1.2229 & -0.015239 & 0.022475 \\
\hline USD/EUR & -0.00010007 & 0.0073187 & 0.1886 & 2.819 & -0.038441 & 0.046172 \\
\hline JPY/EUR & -0.000076826 & 0.0094462 & -0.3122 & 4.1825 & -0.067871 & 0.048382 \\
\hline GBP/EUR & 0.000079687 & 0.0058505 & 0.17458 & 2.455 & -0.026972 & 0.031337 \\
\hline CHF/EUR & -0.00019208 & 0.0053331 & 2.5343 & 39.674 & -0.025 & 0.079215 \\
\hline
\end{tabular}

